\title{
Corpo e poder: as condições de vulnerabilidade da mulher mãe no debate midiático sobre o parto*
}

\author{
Leandro Rodrigues Lage** \\ Danila Cal*** \\ Bárbara Tuanni Veloso da Silva****
}

\section{Resumo}

$\mathrm{O}$ artigo aborda a vulnerabilidade como lugar de problema para se analisar a condição da mulher mãe no debate midiático sobre o parto. Reflete-se sobre a inscrição das mulheres mães e de suas condições de vulnerabilidade nos enquadramentos midiáticos: ora como corpos submetidos ao paternalismo médico $e$ à normatização sexista que culminam nos casos de violência obstétrica; ora como indivíduos capazes de reagir às práticas $e$ normas destinadas à domesticação do corpo da mulher. A vulnerabilidade assume um lugar político decisivo, mas também ambíguo, entre a relacionalidade dos corpos e a reificação da vítima.

Palavras-chave: Vulnerabilidade, Mulher, Parto, Corpo, Poder.

\footnotetext{
* Recebido em 10 de abril de 2019, aceito em 24 de setembro de 2019. Este artigo foi realizado no âmbito do projeto Figuraçóes da vulnerabilidade: linguagens do sofrimento, políticas do comum, coordenado por Leandro Lage, e também a partir da pesquisa Parir, verbo político: Tensóes discursivas sobre o parto, desenvolvida por Bárbara Silva, e do projeto Comunicação, política e gênero: configuraçôes discursivas das mulheres como sujeitos políticos em diferentes âmbitos comunicacionais, coordenado por Danila Cal. Este trabalho contou com apoio da Coordenação de Aperfeiçoamento de Pessoal de Nível Superior (Capes).

**Professor da Faculdade de Comunicação e do Programa de Pós-Graduação em Comunicação, Cultura e Amazônia da UFPA, Belém, PA, Brasil. Coordenador do Grupo de Pesquisa Comunicação, Estética e Política (Cepolis). leandrolage@ufpa.br / orcid.org/0000-0002-6814-9640.

*** Professora da Faculdade de Comunicação e do Programa de Pós-Graduação em Comunicação, Cultura e Amazônia da UFPA, Belém, PA, Brasil. Líder do Grupo de Pesquisa Comunicação, Política e Amazônia (Compoa). danila@ufpa.br/ orcid.org/0000$\underline{\text { 0003-3243-8368 }}$
}

****Mestre em Comunicação, Linguagens e Cultura pela Universidade da Amazônia (Unama), Belém, PA, Brasil. btuanni@gmail.com / orcid.org/0000-0002-8714-5389 
Body and Power: Conditions of Vulnerability of Mothers in The Media Debate about Childbirth

\begin{abstract}
The article considers vulnerability as a touchstone to analyze the condition of the mother in the media discussions about childbirth. It reflects on the inscription of mothers and their conditions of vulnerability in media framings: as bodies subjected to medical paternalism and to a sexist normalization that culminates in cases of obstetric violence; or as individuals capable of reacting to practices and norms that domesticate women's bodies. Vulnerability assumes a decisive, but also ambiguous political place between the relationality of bodies and the reification of the victim.
\end{abstract}

Keywords: Vulnerability, Women, Childbirth, Body, Power. 


\section{Introdução}

Se o pessoal, o privado e o íntimo ocupam, cada vez mais, o centro das arenas onde ocorrem os processos políticos contemporâneos, então o corpo está à montante e à jusante desse vasto campo de ações e resistências. Como nos recorda Lemke (2017), em cada uma das diversas inferências de Foucault sobre as relações de poder, da docilização disciplinar à governamentalidade biopolítica, o corpo é uma das instâncias fundamentais no que diz respeito ao exercício das práticas de saber e formas de poder. Por certo, quando nos referimos ao corpo, em seu vínculo elementar com a política, não pensamos em "um corpo" em particular, e nem mencionamos "o corpo" como entidade fixa, autônoma e universal. O particularismo ao qual recorreremos é, especificamente, o do corpo da mulher, essa outra categoria que os próprios feminismos e estudos de gênero têm tensionado cada vez mais. Mais especificamente, referimo-nos ao corpo da mulher mãe, ou da parturiente, como o discurso médico convencionou chamar.

As experiências da gestação e do parto colocam em jogo tanto os direitos sexuais e reprodutivos quanto a própria autonomia da mulher em relação ao corpo frente às práticas médicas e normas sociais. Daí porque figuram como problema político atravessado por relações de saber e poder que se precipitam sobre o íntimo, interferindo diretamente na autoconfiança - abalada pelas experiências de violência obstétrica - e no autorrespeito - ameaçado pela hierarquia discursiva imposta pela medicina obstetrícia sobre as capacidades da própria mulher mãe para tomar decisões e assumir responsabilidades. $\mathrm{Na}$ abordagem desse problema, o conceito de vulnerabilidade (Butler, 2006, 2015a, 2015b; 2016; 2018) ocupa um lugar ético e político central, mas também ambíguo: por um lado, aponta para as normas que regulam os corpos e suas possibilidades de existência $e$ ação, em sua relacionalidade; por outro, assume o risco de reificação do lugar da mulher como vítima passiva $e$ independente. 
A proposta do artigo é, assim, abordar a vulnerabilidade como lugar de problema para se pensar a condição da mulher mãe no debate midiático em torno do parto. $\mathrm{O}$ argumento que se propõe vai na direção de uma reflexão sobre a inscrição das mulheres mães e de suas condições de vulnerabilidade nesses enquadramentos midiáticos: ora como corpos submetidos ao paternalismo médico e à normatização sexista; ora como indivíduos capazes de reagir às práticas e normas destinadas à domesticação do corpo da mulher.

Como argumenta Arendt (2007), toda luta política requer um "espaço de aparição" para se desdobrar, no qual homens $e$ mulheres podem mostrar, por atos e palavras, quem são $e$ o que podem fazer. Nesse sentido, nem os indivíduos, nem o próprio espaço estão previamente concebidos. Os sujeitos constroem sua própria aparição, ao mesmo tempo em que (re)configuram o espaço no qual o fazem. Os termos dessa aparição têm relação direta, em nossos dias, com o lugar da mídia enquanto âmbito de visibilidade e discutibilidade políticas. O que está em questão é, sobretudo, a possibilidade de se refletir sobre os direitos relacionados à maternidade e sobre como eles vêm à tona no debate midiático em torno do parto, entendendo essa discussão como fenômeno marcado pela troca pública de argumentos, pelo relato de experiências, por processos de prestação de contas $e$ justificação, e pela mobilização cívica (Maia, 2006). Além disso, também está em jogo a própria da ideia de mídia como estrutura social ativa na produção de avaliações e hierarquias sobre sujeitos e modos de vida (Butler, 2015a).

Analisamos um conjunto de 38 matérias publicadas na Folha de S.Paulo, no período de debate sobre a Resolução Normativa 368/15 da Agência Nacional de Saúde sobre o direito de acesso à informação das beneficiárias aos percentuais de cirurgias cesáreas $e$ de partos normais. A resolução foi promulgada em atenção a

\footnotetext{
${ }^{1}$ Dispõe sobre o direito de acesso à informação das beneficiárias aos percentuais de cirurgias cesáreas e de partos normais, por operadora, por estabelecimento de saúde e por médico e sobre a utilização do partograma, do cartão da gestante e da carta de informação à gestante no âmbito da saúde suplementar.
} 
diferentes apontamentos sobre a elevada taxa de cesarianas no país. De acordo com a pesquisa Nascer no Brasil (Leal, 2014), do total de partos realizados no Brasil entre fevereiro de 2011 a outubro de 2012, 48,1\% foram vaginais, $5 \%$ vaginais sem nenhuma intervenção durante o trabalho de parto e 51,9\% cesarianas. O levantamento mostrou ainda que a taxa de cesáreas chega a $89,9 \%$ se considerado apenas os partos de mulheres com maior escolaridade e atendidas pelo setor privado de saúde.

Buscamos analisar como essa mídia organizou enquadramentos relacionados: a) às normas morais que regulam os corpos das mulheres mães; b) às experiências e situações relacionadas à violência obstétrica; e c) à autonomia e ao respeito às decisões das mulheres mães.

\section{A dimensão corporal da vulnerabilidade e o papel da mídia}

Nas últimas duas décadas, o conceito de vulnerabilidade vem assumindo uma relevância política decisiva ao configurar uma base reflexiva e argumentativa para a reivindicação de uma responsabilidade ética para com determinados sujeitos. Os trabalhos recentes de filosofia moral de Butler (2006, 2015a, 2015b, 2016,2018 ) têm um papel importante nesse debate, pois deslocam o conceito das perspectivas feminista e bioética na direção de uma abordagem filosófica, ética e relacional da vulnerabilidade, tornando essa noção produtiva para reflexões sobre as normas morais, a materialização do corpo, as formas de violência, o cuidado e a responsabilidade (Mackenzie; Roger; Dodds, 2014; Shabot, 2016; Gilson, 2016; Sabsay, 2016).

Para Butler (2015a), o corpo, enquanto vetor das relações intersubjetivas, é o domínio por excelência da vulnerabilidade. Não se pode defini-los separadamente, pois a vulnerabilidade possui, necessariamente, uma dimensão encarnada, enquanto que o corpo depende, de maneira fundamental, das redes sociais $e$ políticas em que vive, isto é, das condições materiais $e$ interacionais que o permitem se tornar uma livable life. "O corpo supõe mortalidade, vulnerabilidade, práxis: a pele e a carne nos 
expõem ao olhar dos outros, mas também ao contato e à violência, e são também corpos que nos colocam em perigo de nos tornarmos agentes e instrumentos de tudo isso" (Butler, 2006:52, tradução nossa).

Assim, a relacionalidade definidora dessa noção não reificada de corpo tem pelo menos duas consequências (Sabsay, 2016): em primeiro lugar, força-nos a assumir que nosso corpo nunca é somente nosso, pois possui uma dimensão relacional que lhe é intrínseca e definidora; em segundo lugar, inscreve o corpo em relações de interdependência e mútua afetação. É preciso, ainda, acrescentar a essas consequências aquilo que Mills (2007) aponta, no trabalho de Butler, como uma dimensão fortemente definidora dos processos de materialização e das possibilidades de existência corpórea: a normatividade.

O corpo, portanto, está sempre à mercê de formas de sociabilidade e normas morais que não apenas delimitam sua autonomia individual, como definem os modos pelos quais são apreendidos, reconhecidos, cuidados, ou descartados, violentados, aniquilados. Assim, "ser um corpo é estar exposto a uma modelagem e a uma forma social, e isso é o que faz da ontologia do corpo uma ontologia social" (Butler, 2015a:15-16). Nesse sentido, é a própria vulnerabilidade como condição generalizada que ganha forma, uma vez que está associada às existências e relações corporais nas quais um corpo está sempre ameaçado por outros corpos ou aos riscos que toda vida corporal está sujeita.

A precariedade, para Butler (2015a), não deve ser compreendida como uma condição particular de certas vidas:

O apelo à interdependência é, portanto, também um apelo para superarmos essa cisão e nos movermos na direção do reconhecimento de uma condição generalizada de precariedade. $\mathrm{O}$ outro não pode ser destrutível se eu não sou, e vice-versa. A vida, concebida como vida precária é uma condição generalizada, e sob certas condições políticas se torna radicalmente exacerbada ou radicalmente repudiada (Butler, 2015a:78). 
Assim, enquanto processo socialmente condicionado, correlativo à interdependência entre as pessoas, a precariedade deve ser pensada em termos de igualdade, de condição generalizada, sujeita a dimensões políticas $e$ normativas específicas, que podem acentuar ou mitigar a vulnerabilidade.

$\mathrm{O}$ que faz, então, com que uma vida se torne visível enquanto vida, em sua precariedade, em sua necessidade de amparo e cuidado, na possibilidade de ser perdida e enlutada? E o que nos impede de ver ou compreender certas vidas como vivas, de tomá-las como dignas de cuidado e mesmo de luto? Para essa autora, "o problema diz respeito sobretudo à mídia, na medida em que só é possível atribuir valor a uma vida com a condição de que esta seja perceptível como vida, mas é apenas de acordo com certas estruturas avaliadoras incorporadas que uma vida se torna perceptível" (Butler, 2015a:82). Ou seja, a mídia é considerada, nessa análise, instância privilegiada de produção de enquadramentos, avaliações e hierarquizações sobre sujeitos $e$ modos de vida.

Ao chamar atenção para o enquadramento midiático de certas vidas, Butler (2015a) denuncia a distribuição desigualitária da condição de "vida que importa", gesto cujas implicações incidem sobre nossas "disposições afetivas politicamente significativas". É nesse sentido que a autora distingue a vida precária das condições precárias: nem toda vida precária está entregue a condições precárias de vida; por outro lado, as vidas entregues às condições precárias têm sua precariedade primordial negada, posto que nem consideradas vidas são. E a mídia ocupa um lugar central enquanto poder regulatório que contribui, com seus modos de inscrição dos sujeitos em narrativas, imagens $e$ discursos, para a criação desses níveis diferenciais de conduta afetiva e moral diante de certos sujeitos e corpos.

Daí porque, no debate em torno da gestação e do parto, entram em cena não apenas os direitos e a autonomia da mulher e de seu corpo ante as condutas médicas e os dispositivos legais que regem o parto, mas, sobretudo, as normas morais que regulam esses corpos em sua existência ao mesmo tempo ativa 
(porque agem, produzem, afetam, resistem, gestam) e passiva (porque sofrem, reagem, abalam-se, cansam). Nesse sentido, a vulnerabilidade traz uma solução, mas também um problema. Ao apontar para a relacionalidade dos corpos de mulheres em sua inscrição normativa, reguladora das práticas, essa abordagem também suscita um dilema incômodo: a definição da vulnerabilidade como propriedade fixa do sujeito mulher, reificada como vítima.

\section{Vulnerabilidade e resistência}

Vulnerabilidade é um conceito desafiador para os feminismos. Associado ao dano, à fraqueza, à passividade, à dependência, à incapacidade, à impotência, essa noção assume uma feição negativa que, no entanto, vem a calhar a certos modos de pensar o corpo feminino (Gilson, 2016). Historicamente vinculado às violações sistêmicas, explorações e objetificações, o corpo da mulher abre um feixe específico de relações quando se torna o corpo de uma mulher mãe, e um prisma ainda mais específico quando associado à experiência do corpo em trabalho de parto. Entretanto, diferentes autoras buscam inverter essa apreensão negativa tanto da vulnerabilidade quanto do corpo da mulher mãe, buscando nessa complexa teia de relações indícios de vitalidade e resistência (Shabot, 2016; Gilson, 2016; Sabsay, 2016).

Uma das experiências mais comuns de violação do corpo da mulher mãe é a própria violência obstétrica, em suas variadas formas e manifestações. Segundo Shabot (2016), a Venezuela foi o primeiro país a reconhecer legalmente esse tipo de agressão. $\mathrm{O}$ texto da lei venezuelana estabelece direitos da mulher durante a gestação e o parto, definindo como violência obstétrica formas de "apropriação do corpo e dos processos reprodutivos das mulheres pelos(as) profissionais de saúde" que incluam o tratamento desrespeitoso da mulher mãe, os abusos de medicalização, a patologização de processos naturais, a adoção de procedimentos $e$ 
práticas que ameacem a "autonomia e capacidade das mulheres de decidir livremente sobre seus corpos e sua sexualidade".

Para Shabot (2016),

\begin{abstract}
A adoção de termos e frases como "desumanização", "abuso", "perda de autonomia" e "retirada... da capacidade da mulher para decidir livremente sobre seus corpos e sua sexualidade" sugerem que essa forma específica de violência pode ser melhor compreendida por meio da análise como violência de gênero - e especificamente violência sexual - e objetificação da mulher, em vez de considerá-la uma forma geral de violência médica (Shabot, 2016:237, tradução nossa).
\end{abstract}

Abordando o problema sob esse prisma, a autora chama atenção para pelo menos dois aspectos: em primeiro lugar, ao tomar esse tipo de violação como expressão da domesticação do corpo feminino, Shabot (2016) evidencia a naturalização da violência obstétrica como um conjunto de práticas tidas como regulares; em segundo lugar, reflete sobre a experiência do parto em sua incompatibilidade com uma idealização de "corpo feminino e delicado". Coloca-se, assim, o problema da violência obstétrica como vulnerabilidade às práticas e normas médicas $e$ patriarcais, que consistem em manter as formas de controle $e$ regulação do corpo da mulher mãe.

Entretanto, como argumenta Shabot (2016), a própria experiência do parto é incompatível com uma visão do corpo da mulher como passivo e frágil. Em vez disso, deve-se reconhecer o corpo da parturiente em sua ambiguidade: "o 'corpo feminino' no sentido mais estrito (gestação, realização da tarefa da feminilidade, reveladora da 'essência misteriosa' da mulher), mas também forte, ativo, um corpo criativo" (Shabot, 2016:241, tradução nossa). Nesse sentido, a vulnerabilidade da mulher mãe às práticas médicas $e$ normas morais opressivas ao corpo feminino é convertida numa visão ativa da experiência do parto, do corpo e do próprio sujeito como capaz de reconhecer e resistir a esse tipo de violência. 
A experiência do parto - e mais especificamente a da violência obstétrica - coloca em questão a dupla face da vulnerabilidade, com seus corpos ativos e, simultaneamente, sujeitos ao dano e a violações. Em defesa de uma compreensão da vulnerabilidade como conceito ético e político com potencial heurístico para a reivindicação de uma responsabilidade ética, Gilson (2016) recusa uma abordagem dessa noção como característica intrínseca ao corpo feminino, visto com frequência como delicado, fraco, passivo, dependente e incapaz. Para a autora, deve-se recusar uma abordagem da vulnerabilidade em simples oposição a uma ideia de resiliência:

Concebe-se vulnerabilidade, primeiro, como condição de potência (em vez de fixa); segundo, como fundamental e compartilhada (em vez de desigual e hierarquicamente atribuída); terceiro, como tendo uma diversidade de manifestações (em vez de homogênea); e, finalmente, como experimentada de uma forma ambivalente e ambígua $e$ como tendo um valor ambivalente e ambíguo (em vez de inerentemente negativa) (Gilson, 2016:78, tradução nossa).

Ao pensar a vulnerabilidade nessa chave compreensiva, evita-se tanto a vitimização da mulher enquanto sujeito naturalmente suscetível ao dano quanto sua culpabilização, esteada em normas morais segundo as quais a mulher é vítima de si mesma ao não se adequar às regras que devem orientar seus corpos, suas condutas e seus próprios desejos.

Essa abordagem faz eco aos trabalhos mais recentes de Butler (2016), voltados justamente à dimensão de vulnerabilidade intrínseca à ação política daqueles que tomam as ruas em manifestações em defesa de direitos e em protestos contra formas de opressão e violência. A dimensão ativa da vulnerabilidade reaparece como exposição deliberada aos riscos, em nome da ação política de resistência. 
Para Butler (2016), ainda que

\begin{abstract}
a resistência popular leve à vulnerabilidade, e a vulnerabilidade (no sentido da exposição implicada na precariedade) leve à resistência, vulnerabilidade não é exatamente sobrepujada pela resistência, mas se torna uma força de mobilização potencialmente efetiva nas manifestações políticas (Butler, 2016:14, tradução nossa).
\end{abstract}

Ressaltam-se, nesse sentido, tanto a produtividade política do conceito de vulnerabilidade para se compreender de modo complexo as diversas experiências de violação e resistência na qual estão em jogo as normas que regulam os corpos $e$ as ações dos sujeitos quanto a necessidade de se observar a própria construção midiática e o reforço dessas normatividades. Conforme argumenta Butler (2015a), a distribuição desigualitária da condição de sujeito, de vida que merece ser cuidada, é objeto de enquadramentos midiáticos que nos ensinam de modo rotineiro por quem devemos nos compadecer, e que definem as estruturas morais a partir das quais os indivíduos são vistos como intrinsecamente vulneráveis ou como pessoas capazes de agir $e$ reagir politicamente, em defesa da própria autonomia. Não se trata, portanto, de abordar a violência, mas também de reconhecer certas práticas como violentas, e certos sujeitos como vítimas de práticas e discursos que os vulnerabilizam.

\title{
4. Metodologia e procedimentos da pesquisa
}

Ao abordarmos a vulnerabilidade como lugar de problema para se pensar a condição da mulher mãe no debate midiático em torno do parto, o conceito operatório de enquadramento vem à tona como categoria para refletir sobre a inscrição dos sujeitos $e$ de suas condições de vulnerabilidade nas narrativas jornalísticas. A força operatória do enquadramento reside, a nosso ver, na dupla possibilidade de realização de uma análise voltada tanto para o modo como as textualidades midiáticas enquadram o mundo, tornando acessíveis perspectivas específicas de interpretação da 
realidade, mas também para as molduras que permitem compreender, de modo reflexivo, a situação interativa sob análise, bem como o envolvimento dos atores nela implicados (Mendonça; Simões, 2012).

Analisar um enquadramento, como afirma Butler (2015a), significa necessariamente questionar a moldura, é

mostrar que ela nunca conteve de fato a cena a que se propunha ilustrar, que já havia algo de fora, que tornava o próprio sentido de dentro possível, reconhecível. A moldura nunca determinou realmente, de forma precisa, o que vemos, pensamos, reconhecemos e aprendemos. Algo ultrapassa a moldura que atrapalha nosso senso de realidade; em outras palavras, algo acontece que não se ajusta à nossa compreensão estabelecida das coisas. (Butler, 2015a:24)

O que está em jogo em nossa análise são os enquadramentos enquanto mecanismos próprios do jornalístico que organizam aqueles que devem ser vistos, como devem ser vistos, isto é, as formas pelas quais são inscritos os sujeitos, seus corpos e falas. Como afirma Carvalho (2010), a noção de enquadramento se torna produtiva em pelo menos dois sentidos: em primeiro lugar, para entendermos o acionamento de quadros de referência no processo de construção das produções jornalísticas, de modo a interpretar e dar inteligibilidade àquilo que é abordado; em segundo lugar, para compreendermos os enquadramentos como a construção de modos de ver e entender no centro de disputas de sentido entre diferentes atores sociais.

No debate específico sobre o parto, animado pela publicação da Resolução Normativa 368/15, interessa-nos identificar como diferentes produções jornalísticas acionam atores sociais e, assim, organizam enquadramentos. O corpus deste trabalho é composto por um conjunto de 38 matérias jornalísticas, entre artigos, colunas, entrevistas, reportagens e editoriais, todos publicados pelo jornal Folha de S.Paulo, escolhido pela abrangência nacional, o que o constitui como espaço jornalístico 
de ampla visibilidade, com potencial significativo para alimentar a agenda pública, dar credibilidade a fontes e (re)produzir enquadramentos. A pesquisa considerou matérias publicadas no período compreendido entre dezembro de 2014, um mês antes da publicação da Resolução 368/15, até dezembro de 2015, a fim de capturar os efeitos que a resolução possa ter tido no agendamento do tema. As produções jornalísticas foram coletadas online, a partir do sistema de busca da Folha online. As palavras-chave escolhidas foram "parto natural", "cesárea", "violência obstétrica".

\section{Enquadramentos jornalísticos}

Como vimos anteriormente, a vulnerabilidade possui uma dimensão necessariamente relacional, que depende tanto das condições materiais, formas de sociabilidade e normas morais $e$ éticas quanto dos mecanismos reguladores utilizados para enquadrar certas vidas como dignas de cuidado e para com as quais temos alguma responsabilidade. É nesse sentido que se faz necessário refletir, na esteira de Butler (2015a), mas também da própria trajetória que o conceito de enquadramento recebeu nos estudos em jornalismo (Carvalho, 2010; Motta, 2007; Gonçalves, 2005), sobre como as mídias jornalísticas produzem inteligibilidade $e$ recortes interpretativos sobre o corpo da mulher mãe e sobre a experiência do parto. Nesse sentido, examinamos a atuação das produções jornalísticas da Folha de S.Paulo a partir da convocação de diferentes atores sociais na construção $e$ organização de enquadramentos sobre a) as normas morais que regulam os corpos das mulheres mães; b) as experiências $e$ situações relacionadas à violência obstétrica; c) a autonomia $e$ o respeito às decisões das mulheres mães.

\subsection{As normas morais que regulam os corpos das mulheres mães}

Na cobertura da Folha de São Paulo, notou-se de modo discreto a discussão em torno da vulnerabilidade da mulher mãe às práticas médicas e normas morais opressivas ao corpo 
feminino. Na coluna de Rosely Sayão intitulada Decisóes da Maternidade, publicada no caderno Cotidiano de 24 de fevereiro de 2015, o debate vem à tona, mas sob a forma de uma espécie de dilema moral pernicioso que as mulheres devem enfrentar na maternidade, seja diante das novas regulamentações das práticas médicas, seja frente ao conjunto de rigorosas expectativas sociais em torno da mulher mãe e da escolha do tipo de parto.

[...] De uns tempos para cá, inauguramos a era das patrulhas rigorosas contra determinadas situações que envolvem o parto e a maternidade.

A história toda começa com o parto: qual a melhor maneira de um bebê nascer? [...]

Foi uma jovem mulher, prestes a dar à luz, que me comoveu tanto com suas questões que me inspirou a ter esta conversa. Ela disse que buscou informações a respeito do parto e chegou à conclusão de que o parto natural e em casa seria a melhor opção para o filho. Desde que considerou essa possibilidade, porém, anda aflita, não dorme mais, e sente-se culpada antecipadamente, caso escolha a operação cesariana, mais tranquila para ela (Sayão, 2015).

A comentarista chama atenção para ao menos três aspectos relacionados à maternidade e ao parto: em primeiro lugar, trata do parto como experiência sobre a qual as decisões cabem à mulher mãe; em segundo lugar, ressalta o peso dessa decisão frente às "patrulhas" $e$, consequentemente, à produção do sentimento de culpa pela escolha do tipo de parto diante das pressões sociais; por fim, trata da cesariana como procedimento médico sujeito ou não às "necessidades" e circunstâncias.

Ao narrar a história de uma mulher mãe que, tendo decidido pelo parto normal, sente-se culpada pela possibilidade de, na iminência do parto, optar pela cesariana, Sayão (2015) joga luz sobre a dimensão opressiva de certas normas médicas e sociais em torno do parto. Isto é, enquanto questão relacionada à autonomia e liberdade de escolha, o parto acaba se tornando o 
núcleo em torno do qual orbitam variáveis como a culpa pela escolha entre um método "natural" e outro "medicalizado", a preocupação com a saúde da criança e da parturiente, o desencontro das informações sobre o tipo de parto mais indicado $e$ a própria necessidade de tomada definitiva da decisão.

Nesse sentido, ainda que convertida em indício da capacidade de resistência intrínseca ao corpo da mulher mãe, a vulnerabilidade persiste mesmo diante de uma concepção ativa da experiência do parto, do corpo e do próprio sujeito como capaz de tomar decisões frente às pressões e normas, dessa vez sob a forma da produção da culpa como consequência de idealizações $e$ normatizações sobre o parto. Esse modo de enquadrar a experiência do parto como dilema salienta uma dimensão generalizada da culpabilização, tal como abordada por Gilson (2016). Nesse caso, a mulher se vê numa encruzilhada moral em que, qualquer que seja o caminho tomado, ela própria assume a responsabilidade pela tomada de decisão.

\subsection{As experiências e situações relacionadas à violência obstétrica}

No que diz respeito às experiências reconhecíveis como violentas ou abusivas, chama atenção a recorrência da episiotomia (incisão feita entre a vagina $e$ o ânus para ampliar o canal de parto) como prática associada diretamente à violência obstétrica. Esse enquadramento do problema pressupõe uma associação direta entre os procedimentos tomados no parto e um tipo de preocupação com o corpo da mulher como instância de prazer para o homem. Em matéria intitulada "Tipo de parto não influencia a vida da mulher", foi apresentado estudo desenvolvido por pesquisadores da USP para identificar se as entrevistadas notaram diferença em sua vida sexual após seus partos:

"No Brasil é comum essa conversa de que o parto normal estraga o 'playground' do marido. A pesquisa mostra que a cesárea não traz nenhuma vantagem, não traz nenhuma proteção", afirma a médica Simone Diniz, professora do departamento de saúde materno-infantil da USP. [...] 
"Mulheres submetidas a episiotomias relatam dor por anos. É difícil pensar em uma vida sexual plena sentindo dor", afirma a obstetriz Ana Cristina Duarte, coordenadora do Gama (Grupo de Apoio à Maternidade Ativa).

Para o ginecologista Alexandre Faisal-Cury, pesquisador do Departamento de Saúde Preventiva da USP e autor principal do estudo, a episiotomia pode trazer algum impacto logo após o parto, mas isso tende a melhorar após os seis meses -as mulheres foram avaliadas entre seis e 18 meses após o parto (Colucci, 2015b).

A declaração da médica consultada pela reportagem evidencia a maneira como o corpo da mulher é visto e sob quais normas morais ele é apreendido. Mesmo que o argumento siga na direção da desconstrução do mito em torno do procedimento e de seu impacto sobre a vida sexual da mulher ( $e$ do homem), o debate é todo orientado para que, em primeiro lugar, a violência obstétrica seja quase que automaticamente associada ao caráter invasivo da episiotomia; e, em segundo lugar, para que a incisão no períneo da mulher seja considerada uma conduta estritamente médica, a quem, portanto, cabe a decisão de fazê-la.

Na edição seguinte da Folha de S.Paulo, outra matéria do caderno Folha Mulher, intitulada "Depois de dar à luz, não tive mais vida sexual", diz funcionária pública, reproduz o mesmo enquadramento: a violência obstétrica associada à episiotomia. Dessa vez, o depoimento evidencia com clareza a apropriação do corpo da mulher pelo paternalismo médico e as consequências psicológicas desse tipo específico de abuso.

A funcionária pública Luciana Cunha, 33, por exemplo, afirma que não consegue ter relações sexuais com o marido desde que a filha nasceu, há um ano e meio, em função da episiotomia. [...]

"[...] Após duas horas e dez minutos, ele iniciou o parto. Alargou com a mão o meu períneo, provocando uma laceração. Depois, disse que precisava fazer a episiotomia, mesmo contra a minha vontade. 
Senti muita dor. Não foi um corte grande, mas fiquei traumatizada. Até hoje, quando me lembro do parto, fecho as pernas por instinto.

[...] Pensei em processá-lo, mas o terror de ter que me encontrar com ele frente a frente foi maior do que o meu desejo de justiça.

Desde que a minha filha nasceu, não consigo pensar em ter relações sexuais com o meu marido. Isso já faz um ano $e$ meio. O medo de voltar a sentir dor é algo que me paralisa. [...]" (Colucci, 2015a).

Além da própria violência médica, traduzida pela intervenção cirúrgica não autorizada, chamam atenção a ausência de uma rede de atendimento e cuidado para com a mulher mãe, inclusive diante da necessidade de lidar com uma possível ação judicial, e o impacto psicológico sobre a mulher, que se vê traumatizada pela experiência do parto. Nesse sentido, embora as reportagens descrevam as consequências da naturalização da violência obstétrica - e da episiotomia, mais especificamente como práticas tidas como regulares e, portanto, não questionáveis (Shabot, 2016), elas mantêm um modo de ver o problema como algo associado a uma idealização do corpo feminino sexualmente ativo e submetido às necessidades do prazer do homem.

\subsection{A autonomia e o respeito às decisões das mulheres mães}

Na cobertura jornalística da Folha de S.Paulo, a experiência do parto é enquadrada de modo compatível com uma visão do corpo da mulher como passivo e frágil. Entretanto, essa mesma perspectiva se vê conciliada com uma visão ativa da experiência do parto, do corpo e da mulher como sujeito capaz de tomar decisões, reconhecer $e$ resistir a abusos e circunstâncias que acirram as condições de vulnerabilidade. Na matéria intitulada Mulheres com plano de saúde vão ao SUS em busca de parto normal, ficam evidentes tanto a precariedade da rede de atendimento à mulher mãe quanto a utilização de estratégias para 
que as gestantes tenham suas vontades atendidas, por mais que isso custe abrir mão dos direitos oferecidos pelo plano de saúde:

Tem gente que diz que sou maluca. Mas como o médico começou a colocar dificuldades para fazer o normal, algumas amigas disseram 'vai pro SUS, está todo mundo fazendo isso'. Faço pré-natal com um médico do plano. Para não ter discussão, vou enrolando ele e na hora do parto vou para a Maria Amélia [hospital público] (Versolato, 2015).

A matéria apresenta, ao todo, as declarações de quatro mulheres mães que procuraram a rede pública para realizar o parto normal, em reação às dificuldades impostas pelos próprios médicos e planos para realizá-lo na rede privada. $\mathrm{O}$ que por um lado é indicativo das violências $e$, inclusive, dos abusos econômicos que vitimam as mulheres mães converte-se num enquadramento das formas de resistir a essas pressões e de fazer valer a decisão da parturiente.

Por outro lado, esse modo de compreender o problema também não estabelece a simples oposição entre a assunção da vulnerabilidade e a adoção de uma postura resiliente por parte das mulheres. As próprias mulheres são chamadas a relatar as consequências da escolha pelo parto normal frente à coação pela adoção da cesariana nas redes particulares de saúde:

Também na Maria Amélia, a pedagoga Luana Gonçalves, 30, atravessou a ponte Rio-Niterói para dar à luz seu filho Renzo, em 2013. "O único porém é a enfermaria coletiva pós-parto. Não tem muita privacidade. Você cansada, aprendendo a amamentar, e não tem nem uma cortininha. Fora isso, foi ótimo", diz ela, que tem Unimed (Versolato, 2015).

Além disso, a ambiguidade da experiência do parto também aparece sob a forma da controvérsia e da disputa de sentidos em torno da norma moral que estabelece e idealiza um tipo de parto - 
$e$, consequentemente, define $e$ idealiza um modelo de mulher mãe. Na matéria intitulada Mulheres criam grupos a favor de cesáreas após críticas em redes sociais, o que está em questão é, novamente, o direito de escolha, consubstanciado na própria autonomia do corpo da mulher mãe. Dessa vez, contudo, trata-se do direito de decidir pela cesariana sem precisar "prestar contas" por não ter sentido "as dores do parto", como preconiza um tipo ideal de mulher mãe.

Há quem diga que, para ser uma boa mãe, é preciso sentir as dores do parto. Mulheres que optam pela cesárea reclamam que têm de lidar com o preconceito de ativistas do parto normal, especialmente em redes sociais. Em resposta, elas vêm se organizando em grupos pró-cesárea.

"Elas costumam dizer que somos 'menos mães', que cesárea não é parto", diz Kauane Braciak, 24, administradora da "Mães, cesárea \& cia". [...]

Em 2011, a ativista Nanda Café, do blog "Mamíferas", gerou polêmica ao escrever que a cesárea eletiva era mais criminosa do que um aborto.

"Defendo o direito da mulher ao próprio corpo, tanto que defendo o aborto. Se não quer parir, aborte", afirma (Belmiro, 2015).

Esse modo de enquadrar o problema levanta uma questão importante, sobre a suposta liberdade e autonomia da mulher mãe para decidir sobre o parto. E, a partir da polêmica comparação entre a cesárea e o aborto, vem à tona o conflito entre o direito sobre o corpo e o direito sobre a escolha do tipo de parto. Nesse sentido, como afirma Shabot (2016), a vulnerabilidade é novamente associada a uma forma de violência de gênero que, além de ser exercida pelas próprias mulheres mães, tem como centro problemático a tentativa de controle do corpo da gestante como um corpo que, se quiser ter autonomia e apropriar-se de si mesmo, não pode, em hipótese alguma, recorrer à medicalização. 


\section{O corpo entre o saber-poder $e$ a culpa}

Não é apenas o debate público em torno das experiências de parto que corrobora, em alguma dimensão, o argumento sobre o estreitamento das relações entre o íntimo e o político. Ao observarmos esses enquadramentos midiáticos sobre o problema, a partir dos relatos de experiência e dos discursos médicos enredados, percebe-se essa vinculação a partir da própria relação entre corpo, os mecanismos e práticas de saber e poder $e$ a produção da culpa. O desencontro das informações sobre o tipo de parto mais seguro para a mãe e para a criança e menos sofrido durante o parto e no puerpério, bem como a hierarquia discursiva imposta pelo saber médico, são reveladores de uma dimensão silenciosamente opressiva de certas normas médicas: a produção da culpa em decorrência das idealizações e normatizações sobre o parto.

Referimo-nos, portanto, a relações de poder que não se exercem apenas de um ponto de vista jurídico-discursivo, no qual estaria em jogo sua legitimidade e/ou legalidade, e nem como força coercitiva ou violenta (Lemke, 2017). Trata-se de uma trama na qual o poder se exerce pelo que Foucault chamava ora de "direção da consciência" (2015), no caso do chamado poder pastoral, ora de "condução de condutas" (1995), no caso da governamentalidade biopolítica: "O exercício do poder consiste em 'conduzir condutas' e em ordenar a probabilidade. O poder, no fundo, é menos da ordem do afrontamento entre dois adversários, ou do vínculo de um com relação ao outro, do que da ordem do 'governo"' (Foucault, 1995:244). Referimo-nos, então, às formas pelas quais os mecanismos e tecnologias de poder acionam modos de saber para estruturar, moldar, restringir e orientar o campo de possibilidades dos sujeitos.

Nos casos de experiências de violência obstétrica, de conflitos morais associados à decisão do tipo de parto, e de tensões na relação entre pacientes e médicos diante das normas médicas, o que se revela é o lugar estratégico da racionalidade na sustentação tanto das práticas médicas, quanto do governo de si - 
e no modo como tais condutas recaem sobre o corpo dos sujeitos. De um lado, o discurso médico legitima e normatiza ações que não teriam outra justificação fora do regime médico de verdade. Pelo contrário. Quando deslocados para outros regimes discursivos, tais ações acabam gerando sofrimento e, no limite, o reconhecimento a posteriori das violências sofridas. Do outro lado, são os próprios sujeitos que se veem compelidos a adequar suas condutas às cartilhas dos diretores de consciência de forma que corram um risco menor de sentirem arrependimento ou culpa pelo que decidiram - ou pelo que deixaram de decidir.

Todas essas circunstâncias nos parecem ilustrar formas de regulação e controle do corpo da gestante, da mulher mãe. Situações essas que, em última instância, também revelam linhas de fratura nessas tramas, desenhadas pelos próprios sujeitos em busca de autonomia e da reapropriação de si mesmo. Como argumentava Foucault, o essencial da disciplinarização dos indivíduos não é negativo, não impõe apenas restrições, mas produz subjetividades e corporalidades, orienta condutas, define as possibilidades e nos confronta com nossas próprias vontades, desejos, receios e incertezas.

Se, por um lado, os enquadramentos midiáticos não dão conta de fugir à lógica da compreensão desses corpos à luz do paternalismo médico, da normatização sexista e da moralização do corpo da mulher, o debate instaurado em torno das experiências de gestação, do parto e das inúmeras formas de violência obstétrica levanta o embate em torno da vulnerabilidade da mulher mãe e, sobretudo, da responsabilidade ética que tem o Estado de garantir uma rede de atendimento que reduza essas condições de vulnerabilidade e ampare esses sujeitos em seus direitos sobre si mesmos, sem a ameaça assombrosa da culpa ou responsabilização por escolher ou recusar o parto medicalizado. Medidas como a Resolução Normativa 368/15 da ANS sinalizam com precisão esses momentos em que a "arte de governar" empreendida pelo Estado define os saberes e racionalidades que balizarão o exercício não apenas institucional, mas também social e moral do biopoder. 


\section{Considerações finais}

Ao abordarmos a vulnerabilidade como lugar de problema para refletirmos a respeito da condição da mulher mãe no debate midiático em torno do parto, a intenção era dupla: por um lado, reivindicar a importância da ideia de vulnerabilidade para pensar as mídias e seus modos de enquadrar e lidar com normas morais que definem o valor de certos indivíduos; por outro, demonstrar a relevância do próprio debate midiático como instância privilegiada de reflexão sobre a visibilidade pública dos sujeitos e de suas condições de vulnerabilidade.

A diversidade de enquadramentos sobre as experiências da gestação e do parto revela tensões importantes no que diz respeito à compreensão da vulnerabilidade e da capacidade de agência desses sujeitos: o embate entre práticas opressivas e iniciativas em torno da decisão sobre o tipo de parto; a construção da escolha da mulher mãe como dilema moral entre um processo natural $e$ uma prática médica; e o impacto da violência obstétrica sobre a viabilidade sexual do corpo da mulher mãe.

Nesse sentido, se, por um lado, o corpo da mulher mãe se vê com frequência submetido ao paternalismo médico $e$ à normatização sexista, o intervalo da cobertura sobre o parto também revelou uma forma de compreender o sujeito mulher mãe como indivíduo capaz de reagir frente às práticas naturalizadas $e$ de fazer escolhas difíceis, mesmo diante da ausência de uma rede de atendimento. Ainda que a vulnerabilidade da mulher seja utilizada como subterfúgio para buscar legitimidade para a nova regra sobre a escolha do parto, a própria cobertura demonstrou, por meio de seus diversos enquadramentos, que a experiência do parto não é feita de escolhas fáceis e de decisões tomadas com base em condições plenas de acesso às informações e orientações que tenham como preocupações centrais a autonomia e a saúde da mulher mãe e do bebê. 


\section{Referências bibliográficas}

ARENDT, Hannah. A condição humana. Rio de Janeiro, Forense Universitária, 2007.

BUTLER, Judith. Vida precaria: el poder del duelo y la violencia. Buenos Aires, Paidós, 2006.

- Quadros de guerra: quando a vida é passível de luto? Rio de Janeiro, Civilização Brasileira, 2015a.

. Relatar a si mesmo. Belo Horizonte, Autêntica, 2015b.

. Rethinking Vulnerability and Resistance. In: BUTLER, Judith; GAMBETTI, Zeynep e SABSAY, Leticia (orgs.). Vulnerability in resistance. Durham and London, Duke University Press, 2016, pp.1227.

Corpos em aliança e a política das ruas: notas para uma teoria performativa de assembleia. Rio de Janeiro, Civilização Brasileira, 2018.

CARVALHO, Carlos Alberto de. Sobre limites e possibilidades do conceito de enquadramento jornalístico. Contemporanea-Revista de Comunicação e Cultura, v. 7, n. 2, pp.1-15, 2010. [https://portalseer.ufba.br/index.php/contemporaneaposcom/article/vie w\%20Article/3701 - acesso em 15 mar. 2019].

FOUCAULT, Michel. "Omnes et Singulatim": uma Crítica da Razão Política. Ditos e escritos, volume IV: estratégia, poder-saber. Rio de Janeiro, Forense Universitária, 2015, pp.355-385.

FOUCAULT, Michel. O sujeito e o poder. In: DREYFUS, Hubert L. e RABINOW, Paul. Michel Foucault - uma trajetória filosófica: para além do estruturalismo e da hermenêutica. Rio de Janeiro, Forense Universitária, 1995, pp.231-249.

GILSON, Erinn. Vulnerability and victimization: Rethinking key concepts in feminist discourses on sexual violence. Signs: Journal of Women in Culture and Society, v. 42, n. 1, 2016, pp.71-98. [https://doi.org/10.1086/686753]

GONÇALVES, Telmo. A abordagem do enquadramento nos estudos do jornalismo. Caleidoscópio: Revista de Comunicação e Cultura, Lisboa,

n. 5/6, 2005 , 
[https://revistas.ulusofona.pt/index.php/caleidoscopio/article/view/226 8 - acesso em 15 mar. 2019]

LEAL, Maria do Carmo et al. Intervenções obstétricas durante o trabalho de parto e parto em mulheres brasileiras de risco habitual. Cad. Saúde Pública, Rio de Janeiro, v. 30, supl. 1, pp. S17-S32, 2014 [http://www.scielo.br/scielo.php?script $=$ sci_arttext\&pid=S0102311X2014001300005\&lng =pt\&nrm $=$ isso - acesso em 26 set. 2019].

LEMKE, Thomas. Foucault, governamentalidade e crítica. São Paulo, Editora Filosófica Politeia, 2017.

MACKENZIE, Catriota; ROGERS, Wendy e DODDS, Susan. Introduction: What is vulnerability and why does it matter for moral theory. In: . Vulnerability: New essays in ethics and feminist philosophy. New York, Oxford University Press, 2014, pp.1-29.

MAIA, Rousiley. Mídia e Vida Pública. In: MAIA, Rousiley e CASTRO, Maria C. P. S. Mídia, Esfera Pública e Identidades Coletivas. Belo Horizonte, UFMG, 2006, pp.07-46.

MENDONCA, Ricardo; SIMÕES, Paula. Enquadramento: diferentes operacionalizações analíticas de um conceito. Rev. bras. Ci. Soc., São Paulo, v. 27, n. 79, pp. 187-201, Jun. 2012 [http://www.scielo.br/scielo.php?script $=$ sci_arttext\&pid $=$ S010269092012000200012\&lng =en\&nrm=isso - acesso em 10 abr. 2019].

MILLS, Catharine. Normative violence, vulnerability, and responsibility. differences, v. 18, n. 2, 2007, pp.133-156.

MOTTA, Luiz Gonzaga. Enquadramentos lúdico-dramáticos no jornalismo: mapas culturais para organizar conflitos políticos. Intexto, Porto Alegre, RS, v. 2, n. 17, jul./dez. 2007, pp.1-25 [https://goo.gl/VbVg3r - acesso em 26 fev 2013].

SABSAY, Leticia. Permeable Bodies: Vulnerability, Affective Powers, Hegemony. In: BUTLER, Judith; GAMBETTI, Zeynep e SABSAY, Leticia (eds). Vulnerability in resistance. Durham and London, Duke University Press, 2016, pp.279-302.

SHABOT, Sara. C. Making loud bodies "Feminine": A feministphenomenological analysis of obstetric violence. Human Studies, v. 39, n. 2, 2016, pp.231-247 [https://doi.org/10.1007/s10746-0159369-x] 


\section{Referências de análise}

BELMIRO, Daniele. Mulheres criam grupos a favor de cesáreas após críticas em redes sociais. Folha de S.Paulo, Cotidiano, 08 set. 2015. [https://goo.gl/k4EBsP - acesso em 30 jul. 2018].

COLUCCI, Cláudia. "Depois de dar à luz, não tive mais vida sexual", diz funcionária pública. Folha de S.Paulo, Folha Mulher, 23 abr. 2015a [https://goo.gl/Y4zifw - acesso em 30 jul. 2018].

- Tipo de parto não influencia a vida da mulher. Folha de S.Paulo, Folha Mulher, 23 abr. 2015b [https://goo.gl/dDWAwu acesso em 30 jul. 2018].

SAYÃO, Rosely. Decisões da Maternidade. Folha de S.Paulo, Cotidiano, 24 fev. 2015 [https://goo.gl/vYsy4v - acesso em 30 jul. 2018].

VERSOLATO, Mariana. Mulheres com plano de saúde vão ao SUS em busca de parto normal. Folha de S.Paulo, Equilíbrio e Saúde, 26 jan. 2015 [https://goo.gl/dgcPs4 - acesso em: 30 jul. 2018]. 